\title{
Screening of Aflatoxin-Producing Fungi in Maize and Groundnuts from Three Regions in Tanzania
}

\author{
Kusiluka Agape, Valence M. K. Ndesendo and Sartaz Begum* \\ School of Pharmacy and Pharmaceutical Sciences, St John's University of Tanzania, \\ P. O. Box 47, Dodoma, Tanzania. \\ *Corresponding author,e-mail: sartaj0786@yahoo.com \\ Co-authorse-mails: agapeekusiluka@gmail.com (Agape); vndesendo@sjut.ac.tz; \\ vndesendo@gmail.com (Ndesendo)
}

Received 23 Dec 2020, Revised 28 Apr 2021, Accepted 3 May 2021, Published May 2021

DOI: https://dx.doi.org/10.4314/tjs.v47i2.16

\begin{abstract}
This study screened aflatoxin-producing fungi in maize and groundnuts from Dodoma, Singida and Iringa regions in Tanzania, and assessed the level of peoples' awareness on aflatoxins health effects. One hundred and twenty samples (20 each crop) were collected and inoculated on Sabouraud dextrose agar and one hundred and eleven samples were observed to have fungal growths that were identified to belong to four genera, namely Aspergillus, Rhizopus, Mucor and Dermatophyte with occurrence frequencies of 75, 2.5, 5 and 10\%, respectively. Among the four screened genera of fungi, Aspergillus was observed to be the major aflatoxin-producing fungi. Five species of genus Aspergillus, namely A. flavus, A. parasiticus, A. niger, A. fumigatus, and A. terreus were isolated with frequencies of $39.1,10,7.5,15.8$ and $2.5 \%$, respectively. Macromorphology and micromorphology of isolated Aspergillus spp were also observed using a light microscope. Furthermore, it was noted that the prevalence of fungi and aflatoxins contamination is more in groundnuts than in maize. In terms of awareness in individuals concerning aflatoxins, only 34\% respondents in Dodoma, $29.9 \%$ in Singida and $24 \%$ in Iringa were aware of aflatoxins. Therefore, the creation of awareness and sensitization on aflatoxins health effects to the people is an important part of intervention ways to forestall and control aflatoxins in Tanzania.
\end{abstract}

Keywords: Aflatoxins, Maize, Groundnuts, Aspergillus spp, A. flavus, A. parasiticus, A. niger, A. fumigatus and A. terreus.

\section{Introduction}

Maize (Zea mays) and groundnuts (Arachis hypogaea) are the major crops grown for economic and nutritional values in many tropical and subtropical areas of the world, and are also amongst the most susceptible host crops to Aspergillus spp, fungal species responsible for aflatoxin contamination (Guo et al. 2009). There is also a strong consensus that aflatoxin contamination of staple food crops like maize and groundnuts possesses big threats to public health, trade and livelihoods in Tanzania (Nyagi et al. 2016, Kamala et al. 2018). For example, the outbreak of an acute aflatoxicosis reported in Dodoma and Manyara regions of Tanzania in 2016 resulted into adverse effects like vomiting, abdominal disorders, diarrhea, jaundice and even death due to insufficient knowledge on aflatoxinproducing fungi and aflatoxins contamination (Kamala et al. 2018). The studies on aflatoxins are extensively done elsewhere in the world

609 
Agape et al. - Screening of aflatoxin-producing fungi in maize and groundnuts ...

(Fountain et al. 2015, Kumar et al. 2017, Sserumagaa et al. 2020), while very little researches have been done on aflatoxinproducing fungi in Tanzania (Nyagi et al. 2016, Mohammed et al. 2018, Sasamalo et al. 2018). Therefore, the present study aimed at screening and identifying aflatoxin-producing fungi in groundnuts and maize from selected areas of Tanzania that experience low annual rainfall and high temperature which favor the growth of aflatoxin-producing fungi. The study further assessed the level of awareness on aflatoxins and its health effects in the society.

\section{Materials and Methods \\ Study area}

The samples were collected from three different regions, namely Dodoma, Singida and Iringa regions of Tanzania where Dodoma $\left(6^{\circ} 10^{\prime} 23^{\prime \prime S} 35^{\circ} 44^{\prime} 31^{\prime \prime E}\right)$ and Singida $\left(04^{\circ} 49^{\prime} \mathrm{S}\right.$ $\left.34^{\circ} 45^{\prime} \mathrm{E}\right)$ form part of the semi-arid central zone of Tanzania due to low and erratic rainfall. Dodoma records average annual rainfall of $600 \mathrm{~mm}$ and temperature ranges from 15 to $36{ }^{\circ} \mathrm{C}$ (Wikipedia/Dodoma 2021) and Singida records average annual rainfall of $240 \mathrm{~mm}$ and temperature ranges from 14 to 32 ${ }^{\circ} \mathrm{C}$ (Wikipedia/Singida 2021, World Weather Online 2021). Iringa $\left(7.77^{\circ} \mathrm{S} 35.69^{\circ} \mathrm{E}\right)$ records average annual temperature of $13-25{ }^{\circ} \mathrm{C}$ and the average rainfall is $740 \mathrm{~mm}$ (Wikipedia/Iringa 2021). The screening and identification of aflatoxin-producing fungi in given samples were conducted at Sokoine University of Agriculture (SUA), Morogoro, Tanzania.

\section{Sampling and sample size}

One hundred and twenty (120) maize and groundnut samples (harvested six months before) were collected in May 2020 from the three regions and cultured for fungal growth. Forty samples (20 each crop) were collected from each region making 120 samples in total. The samples were collected randomly from the local markets and households by using sterilized spoons and ziploc bags. The samples were stored at room temperature $\left(25-27{ }^{\circ} \mathrm{C}\right)$ until further use. The sample size was calculated based on an estimated prevalence rate (Habib et al. 2015, Ibrahim et al. 2017). One hundred and eighty (180) people from selected regions responded to the questionnaire.

\section{Growth and identification of fungi}

Finely grinded samples were inoculated into a labeled sterile Sabouraud Dextrose Agar (CM41-Oxoid, UK) medium impregnated with chloramphenicol and incubated at room temperature $\left(25-27{ }^{\circ} \mathrm{C}\right)$ for 3-7 days. Plates were examined grossly for characteristic growth of Aspergillus species such as obverse and reverse color according to the method described by James and Natalie (2001) and Bandh et al. (2012). Czapek Dox Agar (CM0097-Oxoid, UK) was used as secondary differential media for specific identification and growth of Aspergillus species. The media was prepared according to the manufacturer's instructions and sterilized by autoclaving at $121{ }^{\circ} \mathrm{C}$ for 15 minutes. The growths were stained using lactophenol on clean glass slide. The slides were observed under 10x and 40x magnifications of a light microscope and the fungi were identified by observing standard specifications given by Barnett and Hunter (1999) and the monograph by Raper and Fennell (1965) was used for identification of Aspergillus species (Bandh et al. 2012, Ibrahim et al. 2017).

\section{Data analysis}

Data generated through the questionnaire was analyzed using descriptive statistics. The following formula was used:

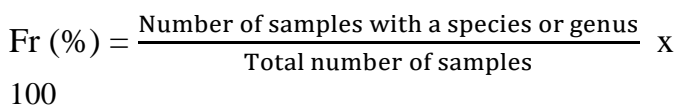
Where; Fr is isolation frequency. The raw data from questionnaire was analyzed by the software program "Statistical Package for the Social Sciences" (SPSS) to get the level of awareness on aflatoxins and their health effects in society. 


\section{Results and Discussion}

The isolation frequency of different fungal genera from maize and groundnuts, prevalence of Aspergillus spp isolated from maize and groundnuts, macromorphology and micromorphology of different Aspergillus spp are presented in Tables 1, 2, 3 and 4, respectively. Furthermore, respondents' awareness on aflatoxins by regions and respondents' awareness on aflatoxins' health effects are presented in Tables 5 and 6 , respectively. Among the one hundred and twenty (120) maize and groundnuts samples, 111 samples were observed to have fungal growths belonging to four genera, Aspergillus, Rhizopus, Mucor and Dermatophyte whose isolation frequencies were $75,2.5,5$ and $10 \%$, respectively (Table 1). Among the four genera of fungi, Aspergillus was observed to be the major one known to produce aflatoxins. Five different species of Aspergillus, namely $A$. flavus, A. parasiticus, A. niger, A. fumigatus, and A. terreus were isolated with occurrence frequencies of $39.1,10,7.5,15.8$ and $2.5 \%$, respectively (Table 2). Macromorphology and micromorphology of different Aspergillus spp isolated were also observed using light microscope (Table 4). Furthermore, it was noted that the prevalence of fungi and aflatoxins contamination is more in groundnuts than in maize (Table 3).

Table 1: Isolation frequency (Fr) of different fungal genera isolated from maize and groundnuts

\begin{tabular}{llllll}
\hline \multicolumn{1}{c}{ Genus } & \multicolumn{1}{c}{ Aspergillus } & Dermatophyte & Mucor & \multicolumn{1}{c}{ Rhizopus } \\
\hline No. of Isolates & 90 & 12 & 6 & 3 \\
Fr $(\%)$ & 75 & 10 & 5 & 2.5 \\
\hline
\end{tabular}

Table 2: Prevalence of Aspergillus spp isolated from maize and groundnuts

\begin{tabular}{llll}
\hline Aspergillus isolated & No. of isolates & Isolation Frequency $(\%)$ & Prevalence $(\%)(\mathrm{n}=90)$ \\
\hline A. flavus & 47 & 39.1 & 52.2 \\
A. parasiticus & 19 & 15.8 & 21.1 \\
A. niger & 9 & 7.5 & 10 \\
A. fumigatus & 12 & 10 & 13 \\
A. terreus & 3 & 2.5 & 3.3 \\
Total & 90 & 75 & 100 \\
\hline
\end{tabular}

Table 3: Prevalence of Aspergillus spp isolated between maize and groundnuts

\begin{tabular}{lccccc} 
Aspergillus spp & A. flavus & A. parasiticus & A. niger & A. fumigatus & A. terreus \\
\hline In Maize & 18 & 8 & 3 & 3 & - \\
In Groundnuts & 29 & 11 & 6 & 9 & 3 \\
\hline
\end{tabular}


Agape et al. - Screening of aflatoxin-producing fungi in maize and groundnuts ...

Table 4: Macromorphology and micromorphology of different Aspergillus spp isolated from maize and groundnuts

Description Macromorphology
Yellow to green
A. flavus
Dark greenish colony
A. fumigatus
Black colony
A. niger

The predominant Aspergillus species observed during the study was A. flavus (39.1\%). This is in agreement with the findings of Fapohunda et al. (2012), Davari et al. (2015), Fakruddin et al. (2015) and Ghaemmaghami et al. (2016, 2020) who reported Aspergillus section flavi to be the predominant species for producing aflatoxins in various feeds. This might have been that $A$. flavus can adapt to different geographical locations especially the sub-tropical and tropical regions of a country. Generally, high water activity and high humidity are favourable conditions for Aspergillus growth (FernándezCruz et al. 2010). Environmental conditions for the production of aflatoxins by $A$. section flavi are $33{ }^{\circ} \mathrm{C}$ and $0.99 a_{w}$ (Milani 2013). Thus, typical hot and humid atmosphere and substandard storage conditions are required to synthesize aflatoxins in agricultural products (Atanda et al. 2013). Some of the metabolites produced by these members of Aspergillus section flavi are well-known to possess encoding genes for aflatoxin production (Ibrahim et al. 2017). Also the prevalence of fungi and aflatoxins contamination was observed to be more in groundnuts than in maize, and this is in agreement with findings of Agbetiameh et al. (2018). 
In terms of awareness of people regarding aflatoxins and its health effects, 34, 29.9and $24 \%$ of the respondents in Dodoma, Singida, and Iringa, respectively were aware of aflatoxins though with minimal knowledge (Tables 5 and 6). Participants who were aware of the fungi mentioned change of taste and unpleasant smell of the food as the effects of mould contamination which led to stomachache and diarrhea. But they were not aware of complicated health issues (Table 6).

Table 5: Respondents' awareness on aflatoxins by regions

\begin{tabular}{llll}
\hline Region & Dodoma & Singida & Iringa \\
\hline Awareness on aflatoxins (\%) & $34 \%$ & $29.9 \%$ & $24 \%$ \\
\hline
\end{tabular}

Table 6: Respondents' awareness on aflatoxins' health effects

\begin{tabular}{llllll}
\hline S.N. & Questions & Yes $(\%)$ & No $(\%)$ & $\begin{array}{l}\text { Don't } \\
\text { know } \\
(\%)\end{array}$ & $\begin{array}{l}\text { Total } \\
\%\end{array}$ \\
\hline 1 & & & & \\
& $\quad \begin{array}{l}\text { Can aflatoxins lead to stomach aches and } \\
\text { diarrhoea? }\end{array}$ & 53.9 & 23.9 & 22.2 & 100 \\
2 & $\begin{array}{l}\text { Can aflatoxins cause teratogenic defects } \\
\text { /death? }\end{array}$ & 15.6 & 53.3 & 31.1 & 100 \\
& Can aflatoxins reduce child growth? & 18.3 & 44.4 & 37.3 & 100 \\
4 & Can aflatoxins cause liver cancer? & 17.2 & 48.3 & 34.5 & 100 \\
5 & Can aflatoxins impair immunity? & 12.8 & 54.4 & 32.8 & 100 \\
6 & Can aflatoxins cause kidney failure? & 19.4 & 51.7 & 28.9 & 100 \\
7 & Can aflatoxins lead to death? & 25.6 & 46.6 & 27.8 & 100 \\
\hline
\end{tabular}

\section{Conclusion}

This study presents the findings on the isolation frequencies of different fungal genera and the prevalence of Aspergillus spp isolated from maize and groundnuts obtained in three regions of Tanzania. The macromorphology and micromorphology of different Aspergillus spp were also shown. The study also revealed that knowledge about aflatoxin producing fungi, aflatoxins and their complicated health effects upon consumption is little known in Tanzania. Therefore, raising awareness and sensitizing people about aflatoxins is an important part of interventions necessary to prevent and control aflatoxins in Tanzania. This could be done by preparing manuals and brochures about aflatoxin-producing fungi and their health effects in Kiswahili and local languages. These materials could be distributed and used for training, conducting seminars and in mass media like radio and television for wider dissemination of the information to the population.

\section{Acknowledgements}

The authors extend their kindest gratitude to all those who supported to accomplish this study. Sincere thanks to Mr. Erick R. Osward of Microbiology Department, SUA for his support. Special thanks to Dr. Stephen S. Nyandoro of Chemistry Department, University of Dar es Salaam for his encouragement and timely advice.

\section{Conflict of Interest}

Authors declare no conflict of interest.

\section{References}

Agbetiameh D, Ortega-Beltran A, Awuah RT, Atehnkeng J, Cotty PJ and Bandyopadhyay R 2018 Prevalence of aflatoxin contamination in maize and groundnut in Ghana: population structure, distribution, 
Agape et al. - Screening of aflatoxin-producing fungi in maize and groundnuts ...

and toxigenicity of the causalagents. Plant Dis. 102: 764-772.

Atanda O, Makun HA, Ogara IM, Edema M, Idahor $\mathrm{KO}$, Eshiett $\mathrm{ME}$ and Oluwabamiwo BF 2013 Fungal and Mycotoxin Contamination of Nigerian Foods and Feeds. In: Makun HA (Ed) Mycotoxin and Food Safety in Developing Countries .InTech, Rijeka, Croatia. 3-38.

Bandh SA, Kamili AN, Ganai BA, Saleem S, Lone BA and Nissa H 2012 First qualitative survey of filamentous fungi in Dal Lake, Kashmir. J. Yeast. Fungal Res. 3: 7-11.

Barnett HL and Hunter BB 1999 Illustrated Genera of Imperfect Fungi (4 ed.). APS Press, St. Paul, Minnesota, USA, pp. 218.

Davari E, Mohsenzadeh M, Mohammadi GH and Rezaeian-Doloei R 2015 Characterization of aflatoxigenic Aspergillus flavus and A. parasiticus strain isolates from animal feedstuffs in northeastern Iran. Iran J. Vet. Res. 16: 150155.

Fakruddin MD, Chowdhury A, NurHossan MD and Ahmed MM 2015 Characterization of aflatoxin producing Aspergillus flavus from food and feed samples. SpringerPlus 4: 159-164.

Fapohunda SO, Moore GG, Ganiyun OT and Beltz SB 2012 Toxigenic Aspergillus flavus and other fungi of public health concern in food and organic matter in southwest Nigeria, Mycology 3: 210-219.

Fernández-Cruz ML, Mansilla ML and Tadeo JL 2010 Mycotoxins in fruits and their processed products: Analysis, occurrence and health implications. J. Adv. Res. 1: 113-122.

Fountain JC, Khera P, Yang L, Nayak SN, Scully BT, Lee RD, Chen ZY, Kemerait RC, Varshney RK and Guo B 2015 Resistance to Aspergillus flavus in maize and peanut: Molecular biology, breeding, environmental stress, and future perspectives. Crop J. 3: 229-237.

Ghaemmaghami SS, Modirsaneii M, Khosrvavi AR and Eazzaghi-Abyaneh M 2016 Study on mycoflora of poultry feed ingredients and finished feed in Iran. Iranian $J$. Microbiol. 8: 47-54.

Ghaemmaghami SS, Pashootan N and Razzaghi-Abyaneh M 2020 Toxigenicity and phylogeny of Aspergillus section Flavi in poultry feed in Iran. Curr. Med. Mycol. 6: 22-29.

Guo B, Yu J, Holbrook CC, Cleveland TE, Nierman WC and Scully BT 2009 Strategies in prevention of preharvest aflatoxin contamination in peanuts: aflatoxin biosynthesis, genetics and genomics. Peanut Sci. 36: 11-20.

Habib MA, Abdu P, Kwanashie CN, Kabir J and Negedu A 2015 Isolation and identification of Aspergillus species from poultry feeds in Kaduna state, Nigeria. Microbiol. Res. Int. 3(2): 27-32.

Ibrahim MJ, Kabir J, Kwanashie CN, Salawudeen MT and Z Joshua Z 2017 Occurrence of mycotoxigenic fungi in poultry feeds at livebird markets, Zaria, Nigeria. Sokoto J. Vet. Sci. 15: 53-59.

James GC and Natalie S 2001 Microbiology: A Laboratory Manual. Benjamin/Cummings Publishing Company, Redwood City, California, USA.211-223.

Kamala A, Shirima C, Jani B, Bakari M, Sillo H, Rusibamayila N, DeSaeger S, Kimanya M, Gong YY, Simba A and the Investigation Team 2018 Outbreak of an acute aflatoxicosis in Tanzania during 2016. World Mycotoxin J. 11: 311-320.

Kumar P, Mahato DK, Kamle M, Mohanta TK and Kang SG 2017 Aflatoxins: aglobal concern for food safety, human health and their management. Front. Microbiol. 7: 2170.

Milani JM 2013 Ecological conditions affecting mycotoxin production in cereals: A review. Vet. Med. 58: 405-411.

Mohammed S, Munissi JJE and Nyandoro SS 2018 Aflatoxins in sunflower seeds and unrefined sunflower oils from Singida, Tanzania. Food Add. Contam.: B 11: 161166.

Nyagi C, Beed F, Mugula JK, Boni S, Koyano E, Mahuku G, Sulyok M and BekundaM 
Tanz. J. Sci. Vol. 47(2), 2021

2016 Assessment of pre-harvest aflatoxin and fumonisin contamination of maize inBabati district, Tanzania. Afr. J. Food, Agric. Nutr. Dev. 16(3): 11039-11053.

Raper K and Fennell DI 1965 The Genus Aspergillus. The Williams \&Wilkins Comp. Baltimore, USA, pp. 686.

Sasamalo MM, Mugula JK and Nyangi C 2018 Aflatoxins contamination of maize at harvest and during storage in Dodoma, Tanzania. Int. J. Innov. Res. Dev. 7: 11-15.

Sserumagaa JP, Ortega-Beltranb A, Wagacha JM, Mutegi CK and Bandyopadhyay R 2020 Aflatoxin-producing fungi associated with pre-harvest maize contamination in
Uganda. Int. J. Food Microbiol. 313: 108376.

Wikipedia/Dodoma 2021: https://en.wikipedia.org/wiki/Dodoma. Retrieved on $28^{\text {th }}$ April 2021.

Wikipedia/Iringa

2021: https://en.wikipedia.org/wiki/Iringa. Retrieved on $28^{\text {th }}$ April 2021.

Wikipedia/Singida https://en.wikipedia.org/wiki/Singida. Retrieved on $28^{\text {th }}$ April 2021.

World Weather Online 2021: https://worldweatheronline.com/Singida. Retrieved on $28^{\text {th }}$ April 2021. 